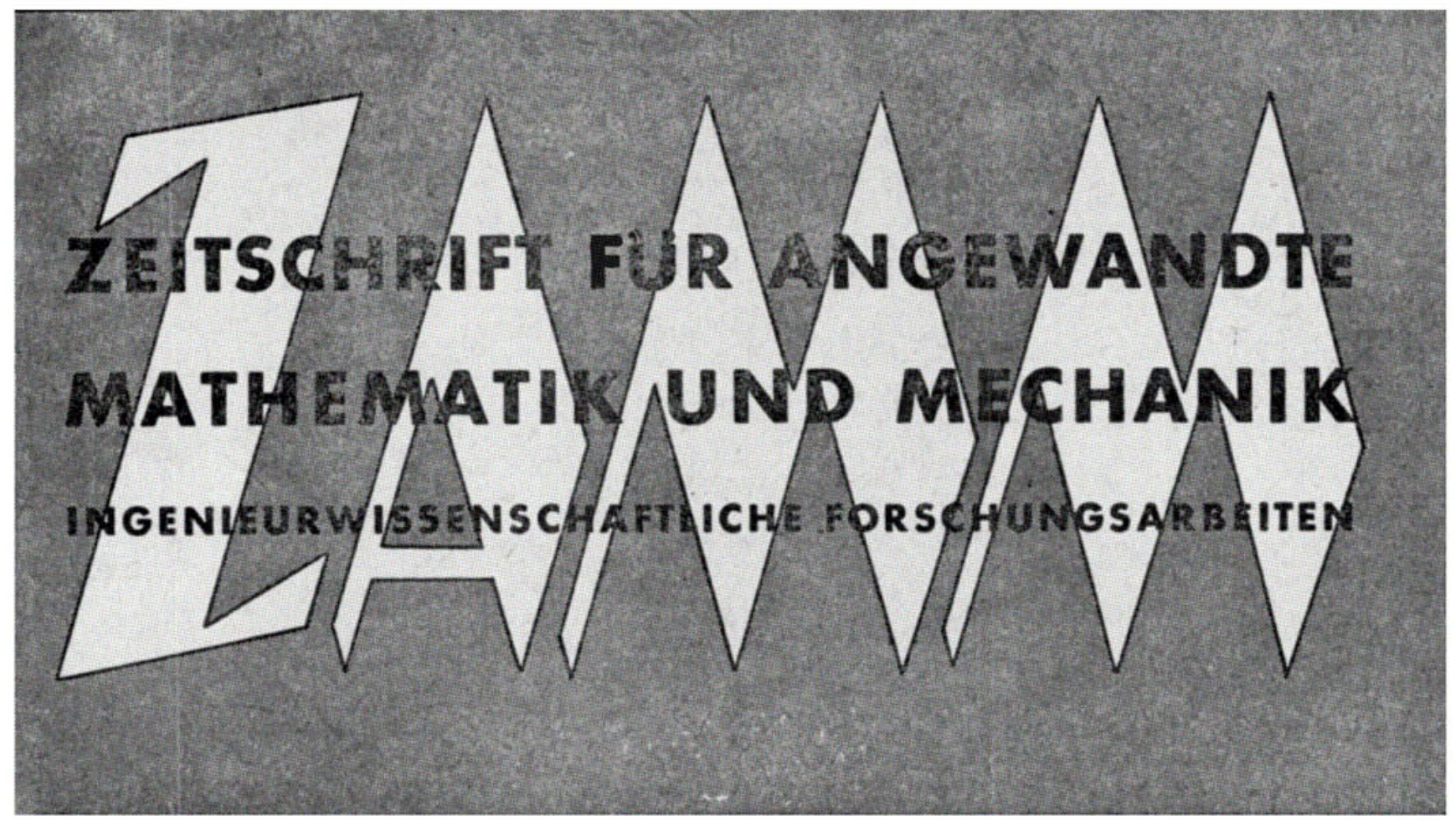

UNTER MITWIRKUNG VON E. BECKER - H. BECKERT - L. BERG - L. BITTNER - L. COLLATZ W. FISZDON - H. GÖRTLER - J. HEINHOLD - K. MARGUERRE - P. H. MÜLLER - H. NEUBER W. OLSZAK · K. OSWATITSCH · A. SAWCZUK - L. SCHMETTERER - G. SCHMIDT K. SCHRÖDER · H. SCHUBERT · H. UNGER - C. WEBER UND F. WEIDENHAMMER HERAUSGEGEBEN VON H. HEINRICH, DRESDEN

\title{
AUS DEM IN HALT:
}

$H A \cup P T A \cup F S \ddot{A} T Z E$

A. N. Sherbourne / H.M. Haydl: Plastic Analysis of Shallow Spherical Shells under Combined Loading at Moderately Large Deflections / K. R. Schneider: Zur Abschätzung der Frequenz nichtlinearer Schwingungen einer Klasse gewöhnlicher Differentialgleichungen / R. M. Markyłan: Anwendung einer indirekten Methode zur Berechnung ebener Unterschallströmungen auf die Berechnung der ebenen, stationären, inkompressiblen Strömung durch Gitter starker Umlenkung / H. Bufler: Elastisches Mehrschichtsystem unter asymmetrischer Belastung

$K L E|N E M I T T E| L U N G E N$

B U CHBESPRECHUNGEN

EINGEGANGENE BÜCHER

NACHRICHTEN

A K A D E M I E.VERLAG GMBH. B E R L IN 